Volume 8, No.6, November-December 2019

International Journal of Science and Applied Information Technology

Available Online at http://www.warse.org/ijsait/static/pdf/file/ijsait20862019.pdf

https://doi.org/10.30534/ijsait/2019/208620198

\title{
Supervised ART-I Artificial Neural Network for Mapping Burned Area Using Landsat TM Images
}

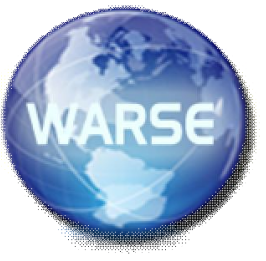

\author{
Kamal R. AL-Rawi ${ }^{1}$, Jose Luis Casanova ${ }^{2}$ \\ ${ }^{1}$ Department of Computer Science, Amman Arab University, Jordan. \\ k.rawi@aau.edu.jo \\ ${ }^{2}$ LATUV, Department of Applied Physics-I, University of Valladolid, Spain. \\ jois@latuv.uva.es
}

\begin{abstract}
Burned area mapping system based on bands 3, 4, 5, and 7 of Landsat TM has been built. Post-fire and pre-post fire images have been used. Supervised ART-I neural network has been employed.
\end{abstract}

Keywords: ART Artificial Neural Networks, Landsat TM, Mapping Burned Areas, Supervised ART-I ANN.

\section{INTRODUCTION}

Mapping burned areas and monitoring forest fires using satellite data is widely used in the last 30 years [1]-[11]. Different approaches have been reported in the literatures for mapping burned areas using Landsat TM images. Maximum Likelihood ML has employed by [2], Regression analysis has been employed by [3], Artificial Neural Networks (ANNs) has been employed by [12]-[14]. They used the Advanced Very High Resolution Radiometer (AVHRR) of the National Oceanic and Atmospheric Administration (NOAA) satellite. [1] showed that band 7 of Landsat TM plays major rule in mapping burned areas. [15] combined Multi-layer Perceptron Artificial Neural Network with one hidden layer and Spectral Angle Mapper Classifiers. [16] employed C5.1 and C6 for classification MODerate resolution Imaging Spectro radiometer (MODIS) images. They claimed that C6 perform better than C5.1.

This study has been conducted to build burned area mapping system based on bands 3, 4, 5, and 7 of Landsat TM images using artificial neural networks. We will employ Supervised ART-I neural network which has been developed by [17].

\section{ART-BASED NEURAL NETWORKS}

ART-based ANNs are gaining publicity due to their stability, rapidity and accuracy [18], [19]. Moreover, unlike Multi-Layer Perceptron (MLP), ART-based ANNs have fixed architectures and can represent subclasses automatically, convergence being assured during the training process. Fuzzy ARTMAP [18] has been employed by [19] for classification remotely sensed data.
The main criticism for ARTMAP [20], and fuzzy ARTMAP as well [18] lie in their complex architectures. Their supervision goes through map field that interfaces two modules of ART. However, Supervised ART-I [17] and Supervised ART-II [21] have been constructed from a single ART module. These two ANNs have, algorithmically speaking, the same classification accuracy of fuzzy ARTMAP. However, they have shorter training time due to their simple architectures. We employed them for classification of a scene of a Landsat TM image [22]. Supervised ART-I ANN will be employed in this study.

\section{METHOD AND DATA}

The network trained with different training sets. It trained with 1000, 2000, and 3000 exemplars. The dynamic learning rate $\beta(0,1]$ and the vigilance parameter $\rho(0,1]$ are set to 0.92 and 0.2 respectively. Post-fire images, as well as multi-fire images are used. Bands 3, 4, 5, and 7 employed. The full architecture and algorithm of Supervised ART-I is in [17].

The fire under study is a large fire that occurred in the province of Valencia, Spain, during 4-13 July 1994. The outside border of the fire has been determined using Global Positioning System (GPS) by the Spanish Forestry Services (SFS). While not every pixel inside the determined area is actually burned, all of them are considered burned by SFS since no data is available inside the burned area. Only 50 pixels represent burned area in the training sets. This represents less than $20 \%$ of the total training set. Classification of burned pixels will be tested by applying post classification filters. Different sizes of post-classification filters will be applied.

\section{RESULTS AND DISCUSSION}

The number of category nodes that represents burned area did not change with training size. It is fixed at 3 category nodes. That because the number of pixels that representing burned area in the training set is fixed. The training time is in order of seconds, while the classification time, for more than $1,000,000$ pixels, is in order of few minutes, using Alpha Digital Station 5000 computer.

\subsection{Post-Fire Images}

During training phase, the network created 21, 25, and 29 category nodes, for unburned pixels, when it trained with 1000, 2000, and 3000 pixels, respectively. The classification accuracy for burned and unburned pixels are $(69.01 \%$, 
Table 1:The system performance with different training size and different filters using post-fire images.

\begin{tabular}{|c|c|c|c|c|c|c|c|c|c|}
\hline \multicolumn{6}{|c|}{ Training Phase } & \multicolumn{4}{|c|}{ Classification Phase } \\
\hline & & \multicolumn{3}{|c|}{ No. of Category Nodes } & \multirow[b]{2}{*}{ time } & \multicolumn{3}{|c|}{ Classification Accuracy } & \multirow[b]{2}{*}{ time } \\
\hline $\begin{array}{l}\text { trainin } \\
\text { g size }\end{array}$ & & $\begin{array}{c}\text { unburne } \\
d\end{array}$ & $\begin{array}{c}\text { burne } \\
\text { d }\end{array}$ & total & & $\begin{array}{c}\text { unburne } \\
\text { d }\end{array}$ & burned & total & \\
\hline 1000 & $\begin{array}{l}\text { no } \\
\text { filter }\end{array}$ & 18 & 3 & 21 & $0.25 \mathrm{~s}$ & $97.11 \%$ & $69.01 \%$ & $88.62 \%$ & $\begin{array}{c}3 \mathrm{~m} \\
45.06 \mathrm{~s}\end{array}$ \\
\hline & $3 \times 3$ & & & & & $95.08 \%$ & $88.21 \%$ & $93.01 \%$ & \\
\hline & $5 \times 5$ & & & & & $93.31 \%$ & $93.66 \%$ & 93.415 & \\
\hline & $7 \times 7$ & & & & & $91.60 \%$ & $96.06 \%$ & $92.97 \%$ & \\
\hline & & & & & & & & & \\
\hline 2000 & $\begin{array}{l}\text { no } \\
\text { filter }\end{array}$ & 22 & 3 & 25 & $0.50 \mathrm{~s}$ & $97.55 \%$ & $62.01 \%$ & $85.81 \%$ & $\begin{array}{c}3 \mathrm{~m} \\
42.16 \mathrm{~s}\end{array}$ \\
\hline & $3 \times 3$ & & & & & $95.66 \%$ & $84.29 \%$ & $92.22 \%$ & \\
\hline & $5 \times 5$ & & & & & $94.02 \%$ & $91.54 \%$ & $93.27 \%$ & \\
\hline & $7 \times 7$ & & & & & $92.50 \%$ & $94.73 \%$ & $93.17 \%$ & \\
\hline 3000 & $\begin{array}{l}\text { no } \\
\text { filter }\end{array}$ & 26 & 3 & 29 & $0.88 \mathrm{~s}$ & $97.73 \%$ & $59.43 \%$ & $86.16 \%$ & $\begin{array}{c}5 \mathrm{~m} \\
56.18 \mathrm{~s}\end{array}$ \\
\hline & $3 \times 3$ & & & & & $95.86 \%$ & $83.00 \%$ & $91.97 \%$ & \\
\hline & $5 \times 5$ & & & & & $94.26 \%$ & $90.83 \%$ & $93.22 \%$ & \\
\hline & $7 \times 7$ & & & & & $92.81 \%$ & $94.31 \%$ & $93.27 \%$ & \\
\hline
\end{tabular}

Table 2: The system performance with different training size and different filters using multi-temporal images.

\begin{tabular}{|c|c|c|c|c|c|c|c|c|c|}
\hline \multicolumn{6}{|c|}{ Training Phase } & \multicolumn{4}{|c|}{ Classification Phase } \\
\hline & & \multicolumn{3}{|c|}{ No. of Category Nodes } & \multirow[b]{2}{*}{ time } & \multicolumn{3}{|c|}{ Classification Accuracy } & \\
\hline $\begin{array}{l}\text { trainin } \\
\text { g size }\end{array}$ & & $\begin{array}{c}\text { unburne } \\
\text { d }\end{array}$ & $\begin{array}{c}\text { burne } \\
d\end{array}$ & total & & $\begin{array}{c}\text { unburne } \\
\text { d }\end{array}$ & burned & total & time \\
\hline 1000 & $\begin{array}{c}\text { no } \\
\text { filter }\end{array}$ & 17 & 3 & 20 & $0.35 \mathrm{~s}$ & $98.08 \%$ & $52.64 \%$ & $84.06 \%$ & $\begin{array}{c}6 \mathrm{~m} \\
09.23 \mathrm{~s}\end{array}$ \\
\hline & $3 \times 3$ & & & & & $93.06 \%$ & $84.19 \%$ & $90.38 \%$ & \\
\hline & $5 \times 5$ & & & & & $91.23 \%$ & $91.96 \%$ & $91.45 \%$ & \\
\hline & $7 \times 7$ & & & & & $89.48 \%$ & $95.06 \%$ & $91.17 \%$ & \\
\hline 2000 & $\begin{array}{c}\text { no } \\
\text { filter }\end{array}$ & 22 & 3 & 25 & $0.91 \mathrm{~s}$ & $99.06 \%$ & $31.74 \%$ & $78.29 \%$ & $\begin{array}{c}7 \mathrm{~m} \\
06.16 \mathrm{~s}\end{array}$ \\
\hline & $3 \times 3$ & & & & & $94.47 \%$ & $70.89 \%$ & $87.89 \%$ & \\
\hline & $5 \times 5$ & & & & & $92.47 \%$ & $85.43 \%$ & $90.71 \%$ & \\
\hline & $7 \times 7$ & & & & & $91.68 \%$ & $91.24 \%$ & $91.55 \%$ & \\
\hline 3000 & $\begin{array}{l}\text { no } \\
\text { filter }\end{array}$ & 24 & 3 & 27 & $2.51 \mathrm{~s}$ & $99.29 \%$ & $25.98 \%$ & $76.66 \%$ & $\begin{array}{c}8 \mathrm{~m} \\
16.01 \mathrm{~s}\end{array}$ \\
\hline & $3 \times 3$ & & & & & $94.80 \%$ & $65.42 \%$ & $85.93 \%$ & \\
\hline & $5 \times 5$ & & & & & $93.36 \%$ & $82.12 \%$ & $89.96 \%$ & \\
\hline & $7 \times 7$ & & & & & $92.07 \%$ & $89.28 \%$ & $91.22 \%$ & \\
\hline
\end{tabular}



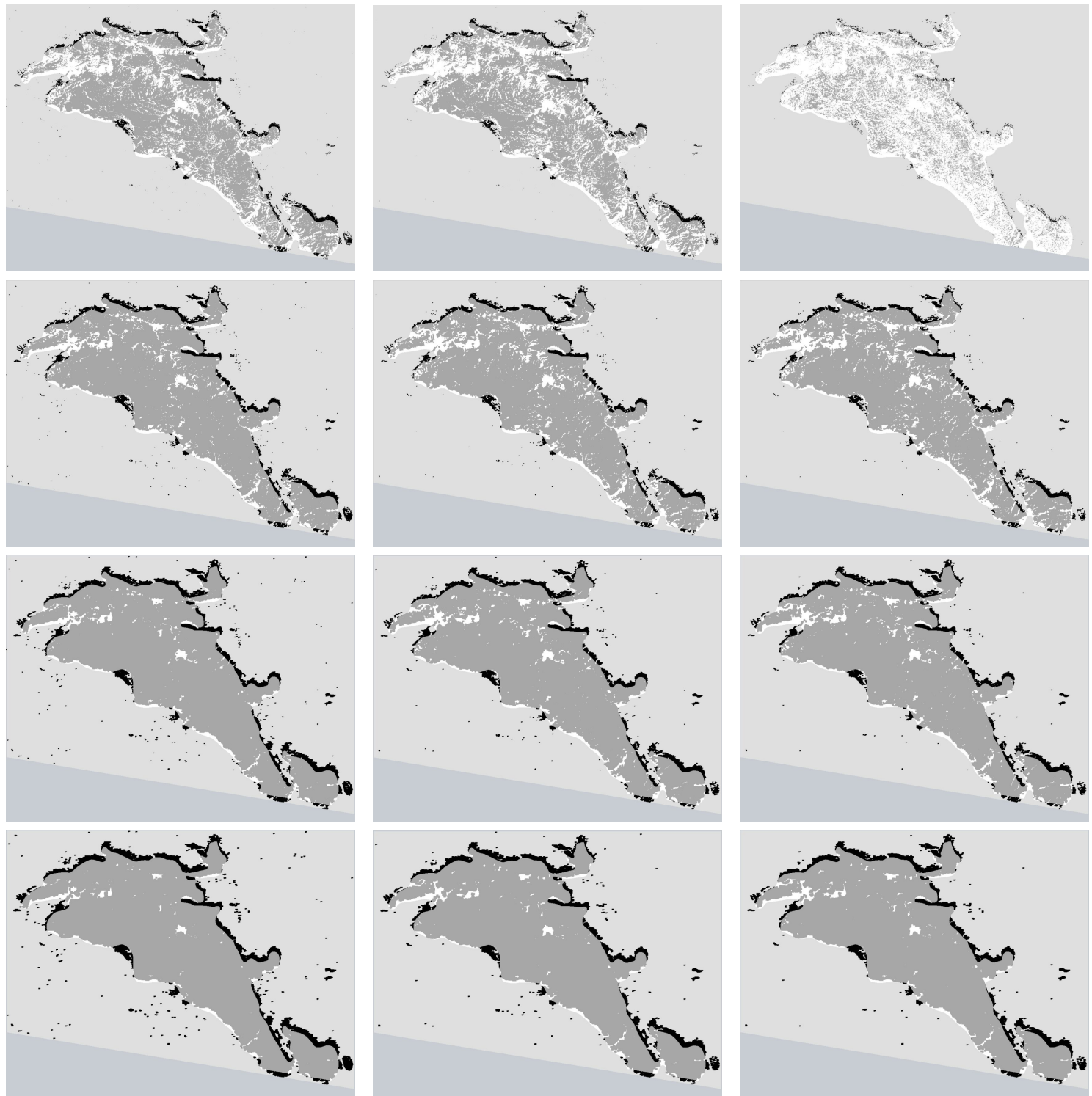

Figure 1: Mapping burned area using Supervised ART-I neural network. Post-fire images have been employed. Bands $3,4,5$, and 7 have been used. The dynamic parameters used for training are; $\rho=0.92$, and $\beta=0.20$. Images in the first raw represent mapped images without applying a filter. Images in second, third, and fourth raw represent mapped images after applying $3 \times 3,5 \times 5$, and $7 \times 7$ filters, respectively. Images in the first, second, and third columns represent mapped images when the network trained with 1000, 2000, and 3000 pixels, respectively. Grey represents burned pixels, which correctly classified as burned by the system. White represents burned pixels, which mis-classified by the system as unburned. Light grey represents unburned pixels, which correctly classified as unburned. Black represents unburned pixels, which mis-classified as burned. The width and length of the study area are $29.130 \mathrm{~km}$ and $35.430 \mathrm{~km}$, respectively. 

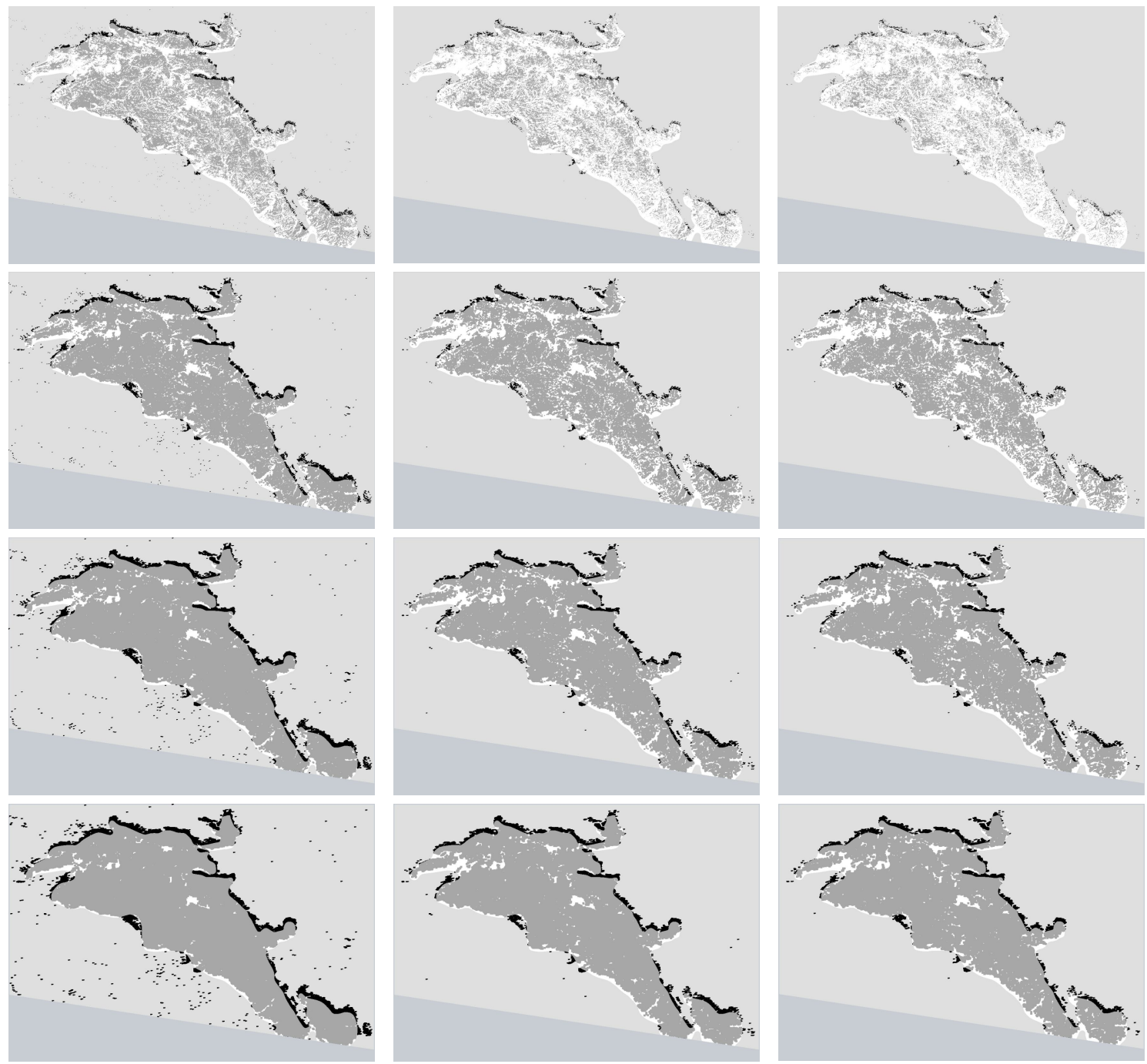

Figure 2: As figure 1, but multi-temporal images are used.

$97.11 \%),(62.01 \%, 97.55 \%)$, and $(59.43 \%, 97.73 \%)$. Such decreases in classification accuracy of burned area with training size compensated by increases classification accuracy of unburned pixels. The classification accuracy of burned pixels has been increased by applying post-classification filters. Different sizes of post-classification filters $(3 \times 3,5 \times 5$, and $7 \times 7$ ) are applied. Please see (table-1 and Fgure-1) for details.

\subsection{Pre-Post Fire Images}

During training phase, the network created 20, 25, and 27 category nodes, for unburned pixels, when it trained with 1000, 2000, and 3000 pixels, respectively. The classification accuracy for burned area decreases when training set increases, while it increases for unburned area. The classification accuracy are $(52.64 \%, 98.08 \%),(31.73 \%$, $99.06 \%)$, and $(25.98 \%, 99.29)$. Please see (table- 2 and figure-2) for details.

\subsection{Post Classification Filter}

The performance of the network for mapping burned area has (7x7) filter increased the performance of the network for mapping burned area from $25.98 \%$ to $89.28 \%$, and increased the overall classification from $76.66 \%$ to $91.22 \%$, using multi-temporal images. However, the classification performance for unburned area decreased from $99.29 \%$ to $92.07 \%$. The system performance behaves the same way when post-fire images are employed.

\section{CONCLUSIONS}

Increasing the number of pixels for training unburned area increases the accuracy for mapping burned area through two causes; better training for their Committed Category Nodes (CCN) by having more pixels for each of them, and more $\mathrm{CCN}$ are generated to represent finer classes. The decreasing of the classification accuracy for the burned pixels when the training pixels that represent unburned pixels is influenced by two factors. First, the real data inside the burned area is not known on pixel level, and we have to know that not all pixels inside the burned areas are really effected by the fire due to many factors (meteorological, topological, and vegetation 
distribution). The second is due to better training for CCN that represent the unburned pixels and due to the generation of more $\mathrm{CCN}$ that represent finer class for unburned pixels. The system have a better performance for unburned pixels inside the boundary of the burned area as unburned rather than consider them as burned which is really not. For these reasons, the burned pixels, which have been mapped by the developed system, represents the real fact rather than considering every pixel inside the boundary of the burned area as burned.

\section{REFERENCES}

M. J. Lopez, and V. Caselles. Mapping burns and natural reforestation using Thematic Mapper data, Geocarto International, Vol. 1, pp. 31-37, 1991.

2. M. C. Pereira, and A. W. Setzer. Spectral characteristic of fire scars in Landsat-5 TM image of Amazonia, Int. Journal of Remote Sensing, Vol.14, No.11, pp. 2061-2078, 1993.

3. D. J. Kushla, and W. J. Ripple. Assessing wildfire effects with Landsat thematic mapper data, Int. Journal of Remote Sensing, Vol. 19, No. 13, pp. 2493-2507, 1998. https://doi.org/10.1080/014311698214587

4. L. Boschetti, P. A. Brivio, H. D. Eva, J. Gallego, A. Baraldi, and J. M. A. Grégoire. Sampling method for the retrospective validation of global burned area products, IEEE Trans. Geosci. Remote Sensing, Vol. 44, No.7, pp. 1765-1773, 2006.

5. G. P. Petropoulos, K. R. Vadrevu, G. Xanthopoulos, G. Karantounias, and M. Scholze. Comparison of Spectral Angle Mapper and Artificial Neural Network Classifiers Combined with Landsat TM Imagery Analysis for obtaining Burnt Area Mapping, Sensors Vol. 10, pp. 1967-1985, 2010.

6. I. Alonso-Canas, and E. Chuvieco. Global burned area mapping from ENVISAT-MERIS and MODIS active fire data. Remote Sens. Environ, Vol. 163, pp. 140-152, 2015.

7. J. V. Hall, T. V. Loboda, L. Giglio, and G. A. McCarty. MODIS-based burned area assessment for Russian croplands: mapping requirements and challenges, Remote Sens. Environ., Vol. 184, pp. 506-521, 2016.

8. R. Ramo, E. Chuvieco. Developing a random forest algorithm for MODIS global burned area classification, Remote Sens., Vol. 9, No. 11, pp. 1193, 2017.

9. M. L. Humber, L. Boschetti, L. Giglio, and C. O. Justice. Spatial and temporal inter comparison of four global burned area products, Int. J. Digital Earth, Vol. 12, No. 4, pp. 460-484, 2018.

10. R. Huang, X. Zhang, D. Chan, S. Kondragunta, A. G. Russell, and M. T. Odman. Burned area comparisons between prescribed burning permits in south-eastern United States and two satellite $\square$ derived products, J. of Geophysical Research: Atmosphere, Vol. 123, No.9, pp. 4746-4757, 2018.

https://doi.org/10.1029/2017JD028217

11. E. Roteta, A. Bastarrika, M. Padilla, T. Storm, and E. Chuvieco. Development of a Sentinel-2 burned area algorithm: Generation of a small fire database for sub-Saharan Africa, Remote Sensing of Environment, Vol. 222, pp. 1-17, 2019.

12. K. R. AL-Rawi, J. L. Casanova, and A. Calle. Burned area mapping system and fire detection system, based on neural networks and NOAA-AVHRR imagery, Int. Journal of Remote Sensing, Vol. 22, No. 10, pp. 2015 - 2032, 2001.

13. K. R. AL-Rawi., J. L. Casanova and A. Romo. IFEMS: New approach for monitoring wildfire evolution with NOAA-AVHRR imagery, Int. Journal of Remote Sensing, VOL. 22, No.10, pp. 2033 - 2042, 2001.

14. K. R. AL-Rawi, J. L. Casanova, A. Romo, and M. Louakfaoui. Integrated Fire Evolution Monitoring System (IFEMS) for monitoring spatial-temporal behavior of multiple fire phenomena, Int. Journal of Remote Sensing, Vol. 23, No. 10, pp. 1967 - 1985, 2002.

15. G. P. Petropoulosa, C. C. Kontoesb, and I. Keramitsogloub. Land cover mapping with emphasis to burnt area delineation using co orbital ALI and Landsat TM imagery. Int. Journal of Applied Earth Observation and Geo information, Vol. 18, pp. 344-355, 2012.

16. J. A. Rodrigues, R. Libonati, A. A. Pereira, J. M. P. Nogueira, and F. L. M. Santos. How well do global burned area products represent fire patterns in the Brazilian Savannas biome? An accuracy assessment of the MCD64 collections, Int. Journal of Applied Earth Observation and Geoinformation, Vol. 78, pp. 318-331, 2019.

17. Abualigah, L. M., Khader, A. T., \& Hanandeh, E. S. (2019). Modified Krill Herd Algorithm for Global Numerical Optimization Problems. In Advances in Nature-Inspired Computing and Applications (pp. 205-221). Springer, Cham.

18. G. A. Carpenter, S. Grossberg, N. Markuzon, J. H. Renolds, and D. B. Rosen. Fuzzy ARTMAP: A neural network architecture for incremental supervised learning of analog multidimensional map, IEEE Transaction on Neural Networks, Vol. 3, pp. 698-713, 1992.

19. G. A. Carpenter, M. N. Gjaja, S. Gopal, and C. Woodcock. ART neural networks for remote sensing: vegetation classification from Landsat TM and terrain data, IEEE Transaction on Geoscience and Remote Sensing, Vol. 35, pp. 308-325, 1997. 
20. G. A. Carpenter, S. Grossbergh, and J. Renold. ARTMAP: Supervised real-time learning and classification of nonstationary data by a self-organizing neural network. Neural Networks, Vol. 4, No. 5, pp. 565-588, 1991. https://doi.org/10.1016/0893-6080(91)90012-T

21. K. R. AL-Rawi, C. Gonzalo, and A. Arquero. Supervised ART-II: A new neural network architecture, with quicker learning algorithm, for classifying multi-valued input patterns, Proceeding of the European Symposium on Artificial Neural Networks ESSAN-99, Bruges: Belgium, pp. 289-294, 1999.

22. K. R. Al-Rawi, C. Gonzalo, and E. Martinez. Supervised ART-II for classification Landsat TM image, 19st Symposium of European Association of Remote Sensing Laboratories (EARSeL), Valladolid, Spain, pp. 229-235, 2000. 